\title{
Verbs Expressing Wish and Their Modality Features in Modern English
}

\begin{abstract}
Sevil Elchin Gurbanova
Correspondence: Sevil Elchin Gurbanova, Department of Innovations in Teaching and Further Education, Azerbaijan University of Languages, Baku, Azerbaijan. E-mail: s.gurbanova@yahoo.com
\end{abstract}

Received: September 7, 2012 Accepted: October 10, 2012 Online Published: November 29, 2012

doi:10.5539/ijel.v2n6p80 URL: http://dx.doi.org/10.5539/ijel.v2n6p80

\begin{abstract}
In this article the study of the modality features of verbs expressing wish in modern English is carried out. Modality is a semantic-grammatical category which expresses the attitude of the speaker to the discourse. It is frequently targeted for its subjectivity, meaning and contextual expressions. Modality features of verbs expressing wish has been thoroughly researched, the latest achievement of different linguists on this topic have been investigated. A new approach on modality of the verbs expressing wish has been given in the result of the article.
\end{abstract}

Keywords: modality features, optative modality, objective meaning, official and non-official communication

\section{Introduction}

This article deals with the modality features and functions of verbs expressing wish in modern English. In the English linguistics study of modality of verbs, including modal words on which a number of scientific works have been written, have always been in the focus of attention of the scholars. In the dictionary of linguistic terminology modality has been given as the attitude of the speaker towards the expressed thought, as grammatical semantic category expressing the attitude of the objective reality towards the thought which is expressed. (Akhmanova, 1966) Some linguists have studied modality functions of a number of verbs, existing in the English language. In spite of the fact that a number of scientific works have been devoted to the study of wish as the modality of verbs in linguistics, this problem is still causing the subject of dispute among the linguists. Though wish is not accepted as modality by the logical semantics, a number of scholars have assumed wish as the meaning of modality and have made attempts to prove this thesis. (Ballie, 1955; Bogdanov, 1977) Some of these authors determine modality parameters as a theoretical basis for their classification and each of which plays a certain role in determining modality. It includes, for example, the attitude of the speaker to the situation (assessment), the status of the situation directed to real attitude (irreality) etc. The second model appeared on the boundaries of diachronic morphology theory being one of the functional theories. In this case wish is affirmed. It often exists in association with diachronic modality. (Bybee, 1994) Though they belong wish to modality, they introduce its meaning as something nearer to the meanings of "encouragement", "longing for". A. Bondarenco notes that meaning of "wish" is a type of modality, and it expresses objective situation of a person and gives special modality expressing grammatical forms to the verbs such as "to wish", "to want", "to desire". (Bondarenco, 1979) But other investigations suppose that one structure of the verbs denoting "wish" and "desire" express modality but the others' don't. (Alisova, 1971; Benosova, 1972; Grepl, 1978) Some scholars evaluate modality of the verbs expressing modality as something emerging from the meaning of "obligation". M. Swan notes that modality in the English grammar expresses possibility and obligation. (Swan, 2001) D. Layons associates wish and intention with obligation. (Lyons, 1978)

J. Kurylowicz when belonging the meaning of wish to modality widely, uses the term "optative". (Kurylowicz, 1964) O. V. Shestakova also uses the meanings of optative with pure wish in close to each other meanings and irrespective of the realization of the wish he accepts them similar to each other in the meaning, as they both express the meaning of "wish". (Shestakova, 1995)

O. N. Novikova has also characterized the meaning of modality. In this respect the scholar revealing the role of each component of the sentence in the creation of modality contents determines the relativity of wish modality, analyzes text creating quality of the considered sentences. He indicates that depending upon the fact whether modality is characterized as the category of logics of linguistics the status of conception of wish among the 
modal meanings is determined differently. As to the investigator modal meanings expressed by the verbs denoting the meaning of wish which participates in the structure are determined by taking into consideration the subject of speech, subject of wish, and also predicate modality and mutual concrete speech situations. Wish modality is existing in mutual impact with aim. The basis of mutual influence of those being in the process of communication contains the attitude of speaker and listener to the event, necessity or unnecessity of the realization of the event and the direction of the event. (Novikova, 1989)

\section{Material Studied}

It is considered that the verbs denoting the meaning of wish, during their syntactic-semantic analysis in the sentence, important categories associated with the conception of wish driven from the contents must be taken into consideration. As to O. N. Novikova, it is necessary to take into consideration different colorings characteristics for each type of wish, to determine the character of the attitudes between the modality of wish with the category of affirmation or (negation), to study the circle of impact of the meaning of wish within the text, to make clear in which attitudes can the sentences with the verbs denoting wish can be in relations with other sentences within the contents. (Novikova, 1989)

I. G. Jirova's thoughts on the modality of verbs expressing wish is also of interest. The investigator in his research work called "Semantic field of verbs denoting wish in the modern English language" while analyzing the agreement of verbs expressing wish, speaks of valency of verbs on certain language, more exactly speaking, lexis conception. I. G. Jirova determines two semi-groups in the composition of group of verbs denoting wish on the basis of the analyzed words:

1) verbs denoting wish which have tendency to modality

2) verbs denoting wish which have no tendency to modality

Verbs agreeing only with nouns within the construction are included into the list of the verbs of wish not having tendency to modality. These are "to crave", "to covet", "to thirst for/after", "to lust for", "to sigh for", "to pant for", 'to itch for", "to burn for", "to care for" and other verbs.

But the verbs agreeing only with nouns but also with infinitive within the construction are expressed with the verbs of wish which have more tendency to modality. It includes verbs such as "to desire", "to want", "to wish", "to long for", "to hunger forlafter", "to die for", "to pine for", "to yearn for", "to emulate". (Jirova, 1990)

E.P.Vasilyeva has investigated intentional conceptions and means of their expressions in English directed to modality. Expression of speaker's will in the process of communication is one of the important forms of manifestations of modality. E.P.Vasilyeva discriminates directive expression of will from the forms of will expressions denoting non-directive expressions of subjective thirst for and he includes into the circle of influence of will expressing of both, addressed (aim-denoting) and the unaddressed (denoting will) will expressions. During the addressed will-expression the addressee becomes the obligatory component of the semantic structure of the expression, and here the person realizing the wish of the speaker is intended. During the addressed will expression it is not important for the speaker who is listening to him, this modality attitude does not require any other object. E. P. Vasilyeva sees the modality of wish in the addressed form of will-expresser.

E. P. Vasilyeva has introduced wish expressing modality in objective optative modality in the widest form.

1) The author includes into the first group the verbs denoting passionate, strong desire and wish, such as to desire, to long for, to covet, to lust

2) The verbs as "to want", "to wish", "to will" are included into the second group. The willfulness expressed by these verbs is weaker in comparison with the verbs mentioned in the first group, such as "to desire", "to long", "to covet", "to lust".

3) Into this group are included such verbs and verbal constructions expressing will in which in comparison with the previous groups of verbs the contents of wish are weaker. The following verbs are included into this group:

"to intend", "to be going" + infinitive, "to have a mind", "to be in spirits", "to be in a mood"

4) Into the fourth group of expressions of grammatic forms of "Present Subjunctive" not excluding the fulfilment of the stated a actions are included, such as:

"would / should like" + infinitive, "would sooner / would rather", "had better", "would / should be glad", "sooner had" + infinitive

All these means express wish, longing which are not insistent as to their degree of intensivity.

5) The last group involves means expressing the idea of unreal wish. Here realization of the action, which is 
spoken on, either is problematic for the speaker or in general seems to be unreal. This content is possible thanks to the usage of different types of conditional characterizations not obeying the verb "to wish" in the subordinate clauses with the contents of object. (Vasilyeva, 1999)

Some other linguists consider the verbs denoting wish as boulomaic modality as a type of dynamic modality, as it has a "person". M.R. Perkins notes that indication of a person drives from the wish of a person and it is like deontic volitive modality. (Perkins, 1983) But Palmer suggests that 'bouletic' would be etymologically preferable (Palmer, 2001) Though such expressions as "it is hoped/desired/feared/regretted that...." are belonged to modality, N. Rescher and P. Simpson introduce the verb "to want" as modality only. (Rescher, 1968) (Simpson, 1993)

R. A. Latipov too in his investigations has touched upon the problem of modality of the verbs denoting wish. The author notes that wish not depending on whether it is real or unreal always bears potential contents. The characterization of obligatory modality between the object and its features is taking place in a certain time (past, present, or future tenses). Verbal predicate of present tense expresses modal attitude towards the reality. But those which express past tense states suspicious attitude to the reality or to its realization. (Latipov, 1992)

O. V. Khanina in her investigations notes that the concept of modality exists in narrow and wider senses. The wider understanding of modality is based upon any evaluative attitude of the person towards the reality and at this time thought, emotion, understanding notions may be completely valued as lawful representation of modality. Verbs denoting wish as to their features often do not differ from the verbs expressing emotion, thought, and understanding which makes it possible to belong them to a proper group. Verbs denoting wish in most languages of the world never join the modal verbs. (Khanina, 2004) Hereon we may come to the conclusion that O. V. Khanina too affirms the modality of verbs expressing wish.

Despite the verbs denoting wish are belonged to the group of wish verbs or hypothetic modality, their differences are also indicated. In the hypothetic modality as to the existence of fact, the realization of wish is expressed as possible. In the wish modality the desire to realize the fact and the wish find their reflections. $(49,9)$

O. B. Shestakova in her research work has investigated the modality of verbs denoting wish and has valued them as the form of manifestation of subjective modality of verbs denoting wish to be studied from the functional-syntactic and pragmatic aspects. The author notes that the subjective modality determines the contents of the subjective attitude as wished and unwished factors.

Besides that, O. B. Shestakova stresses the fact of belonging of the expression of contents of the subjective modality to the different language levels. (lexic, morphological, and syntactic levels). To the lexic level belong such language units, in which content of wish is expressed by the wish nuclear of these units. Here belong verbs to want", "to wish", "to desire", "to long", "to crave"; adjective "desirable"; also verbs possessing the meaning of wish in them such as "to hope", "to look forward", "to be eager", "must" and other units of lexic type. To the morphological level belong the oblique and imperative moods. But to the syntactic level belong such constructions as "to be willing to", "if only", "would like", "would love" and other type of constructions such as "let it be", "may the rain come", "long live the king". O. B. Shestakova thinks that the choice of any of these means is determined a great deal by the impact of factors of pragmatic character, and it is closely associated with the atmosphere of intercourse.

The author related with these themes, notes the following parameters as the most important factors:

1) The subject of wish indications of age, psychological and other character features of the subject

2) The character of the wish (it is realized or unrealized)

3) On whom the realization of the wish depends

4) The character features of the object of wish

5) The highest degree of the wish

6) Time limits of the state of wish

7) Suitability to other modal meanings

O. B. Shestakova pays special attention to the subjective contents of wish and stresses the fact of much dependence of this factor on the communicative focus of the expression. The contents of wish are expressed by the verbs denoting wish. In this case taking the degree of highness of the expression of wish is taken into consideration in the choice of this or that verb which is the main factor.

For example: 
To want - to long

To wish - to crave. (Shestakova, 1995)

It is evidently observed from above mentioned issues that $\mathrm{O}$. B. Shestakova doesn't deny the modality of the verbs denoting wish, but she specifies only the subjective modality of the verbs of this group, denoting the contents of wish. In the study of the author subjective modal contents of wish are observed in both simple and hybrid speech acts. Speaking of hybrid acts the author intends to mean speech acts involving the activity contents of different types. (Shestakova, 1995)

\section{Research Methodology}

\subsection{Research Questions}

The paper aims to investigate the modality features of verbs expressing wish in Modern English. The study attempts to address the following two questions:

1) Do all verbs expressing wish in English have modality features?

2) How do they express modality in different contexts?

\subsection{Method}

The researches of different linguists were analyzed theoretically and comparatively. Referring to the preferred concepts, the verbs expressing wish were studied in details pragmatically and grammatically. By using different literature, the verbs expressing wish were analyzed and modality features of the verbs were investigated in different contexts.

\section{Scope of the Study}

Researching the modality of the verbs of wish it could be stated that especially verbs of this group such as "to will", "to wish", "to want" expresses more modality than the other verbs belonging to this group. Let us consider the modality of the verb "to want" among this group of verbs.

First of all, it is necessary to note that the verb "to want" is used in two modusus - objective and subjective. In the objective modus it states the meanings of obligation and demand, i.e. this verb factually approaches as to the meaning to the verbs "must", "ought to", "need" and other verbs. The objective meaning of the verb "to want" as a rule is a deontic complex expressing the obligation of the necessity, its modality etc. But this verb politely expresses these meanings of obligation that's why it is more used than the other verbs denoting directly, clearly the meaning of obligation. On the other hand the verb "to want" is characterized by the subjective semantic, i.e. it expresses personal wish, mood, desire and in its this quality. This is a strong volitive syntagm as "to have a great desire". The presuppositive -implicative meanings of the saying having the verb "to want" in its composition can be understood as its meanings associated with context and thus it can be considered not as paradigmatic meaning but as syntagmatic meaning. Here belong wish modifications of emotive load, also paradigmatic meanings differing by the different shades of meanings expressing advice, offer, suggestion, order, demand, sentence etc. The subjective meaning of the verb "to want" is of emotive shade of meaning. This verb practically occupies a major place in all the fields of linguistics, but in practice mostly the objective meaning of the verb is realized.

The objective meanings of verb to want are determined by the factors of foreign environment; is conditioned by the subjective meanings of the speaker such as his / her spiritual state, wants, desires, naughtiness, insistence, i.e. by the character of inner emotional state of the speaker.

R. A. Latipov too, mentioning the meanings of the verb "to want" has stressed the meaning of modality of the verb "to want" (Latipov, 1992).

It is necessary to stress the fact that both official and non-official contexts are determined from the social point of view. In the official contexts communication among the people of lower and higher ranks take place, here the distribution of desire has been seriously class-distinctioned and besides in the official communication approximately people in the same social positions and states can take place; here the choice of verbs of wish is less determined. In the non-official communication social distinctions have either not been made or it is made in the lowest degree. Here the attitudes of relationship appear in the front line. The verb "to want" in the official communication acquires the meaning of objective, obligator, but in non-official communication it expresses modality in the objective modus.

"I want to know about this thing now from beginning to end" - he began. "Whose child is that?" (Th. Dreiser, Jennie Gerhardt) 
In the above mentioned sentence chosen from fiction the usage of the verb "to want" is determined by the objective reality. Here the desire of the subject to be aware of the happening events is expressed by the modality of the verb "to want".

F. R. Palmer notes that the verb "to want" has no modality in the official communication and states that it acquires semantic closeness to the expressions "will" and "to be willing". (Palmer, 2001)

We'd like to mention that the verb "to want" apart from the context can express neither objective, nor subjective meanings. Only context here can be the determinative factor of the objective or the subjective meanings of this verb. The verb "to want" apart from the frame of context has possessed very general integral meaning and this can be explained as a means of expressing the wish. This verb expressing only the meaning of wish or desire, apart from the context, can be accepted as a verb denoting wish and it is necessary to note its modality only associated with the context.

Among the list of verbs denoting wish, the verb occupying a self-belonging place expressing the modality of the verb "to wish" must also be mentioned. We may belong the infinitive construction of the verb "to wish" to optative modality, but its unreal subjunctive form to the hypothetic modality.

"They arise chiefly from what is passing at the time, and though I sometimes amuse myself with suggesting and arranging such little elegant compliments as may be adapted to ordinary occasions, I always wish to give them as unstudied an air as possible" (J.Austen, Pride and Prejudice).

We'd like to mention that only the present tense form of unreal wish expresses hypothetic modality.

"I wish I could say anything to comfort you", replied Elizabeth; but it is wholly out of my power. You must feel it; and the usual satisfaction of preaching patience to a sufferer is denied me, because you have always so much" (J.Austen, Pride and Prejudice)

In the system of expression of modality of verbs expressing "wish" the construction "I'd like" occupies a special place. This construction belongs to the field of read movement, but it in most cases expresses wish full of suspicions. This is the situation in which a speaker expresses his / her wish but its realization does not depend on him / her, but on the partner in the situation and on the surrounding situation. The construction "I'd like to" is used by the subject only for the reason that he is not sure of the realization of his wish"

"I thought I'd like to see you again, Lester." - Robert remarked, after they had clasped hands in the customary grip. "It's been a long time now - nearly eight years, hasn't it? (Th. Dreiser, Jennie Gerhardt).

The verb "will" as a verb expressing wish in the English Linguistics is used in the following verb forms:

1) As an auxiliary verb to form future indefinite tense;

2) As a notional verb in the meaning of "to wish", "to want";

3) As a modal verb

F. R. Palmer belongs the modality of the verb "will" to the dynamic modality expressing ability and desire. (Palmer, 2001)

But it is noted that modality denoting the past in English is expressed by the verb "will" (Palmer, 2001). But in the other sources the modal verbs "will" and "won't" are belonged to the volitive modality and it is said that by the use of this verb the desire and attitude of the speaker are expressed. (Tsangalides, 2009)

The verb "will" used as a modal verb in the first person singular expresses desire and decision. This is the meaning which this verb expresses its meaning as a modal verb. As we know, the verb "to will" in English expressing its meaning as "to wish", "to intend" is also accepted as a notional verb expressing "wish". Even as a notional verb, this verb finds its modal meaning in linguistics. As a modal verb "will" like other modal verbs can't change as to the persons or take other tense forms. But "to will" as a verb expressing wish expresses all the functions of verbs by itself and at the same time it expresses modality as well. Here we may belong the construction "to be willing" from the verb "to will".

"I don't care what they say. I shall go on just the same. I know I've got it in me. I feel I am an artist. I'd sooner kill myself than give up. Oh, I shan't be the first they've all laughed at in schools and then he's turned out the only genius of the lot. Art's the only thing I care for: I'm willing to give my whole life to it. It's only a question of striking to it and pegging away." (S. Maugham, Of Human Bondage)

In the above - mentioned specimen chosen from the literary piece in the wish of the subject weak - will finds its reflection. Subject merely expresses his / her desire. The modality expressed here can be compared with modality in the sentence "I can give my whole life to it". 


\section{Result}

Taking all above - mentioned into consideration, we come to the conclusion that the verbs denoting "wish" can express the modality by the enumerated sema beginning from strong wish to the weaker one. Into the list of such verbs only verbs used with particle "to" are included. Other verbs as "to crave "to covet", "to thirst" for / after "to lust for", "to sigh for", "to pant for", "to itch for", "to burn for", "to care for" are the verbs having tendency to modality. They have modality, but not strongly expressed and their modality can only be observed in context.

\section{References}

Akhmanova, O. S. (1966). Dictionary of linguistic terms. Moscow: Encyclopedia

Ballie, Sh. (1955). General linguistics and issues of the French language. Moscow: Foreign Language Publishing.

Belyayeva, E. I. (1985). Functional-semantic background of modality in English and Russian. Voronyoj: Voronjoy University Press.

Benosova, E. (1972). On the semantic description of verbal modality. Prague Studies in Mathematical Linguistics, 1972(4).

Bogdanov, V. V. (1977). Semantic-syntactical organization of sentence. Leningrad.: Leningrad State University.Press.

Bondarenco, V. N. (1979). Forms of modal meanings and their expressions in language. Philological sciences, 1979(2).

Bybee, J. (1994). The evolution of grammar: Tense, aspect, and modality in the languages of the world. Chicago: The University of Chicago Press.

Grepl, M. (1978). Linguistics in Checkoslavakia: About the essence of modality. Moscow: Progress.

Jirova, I. G. (1990). Pragmatics and methodology of teaching foreign language: Experiment of compatibility analysis of verbs expressing wish in Modern English. Moscow: Moscow University Press.

Khanina, O. V. (2004). Wish: Cognitive-functional portray. Linguistics Issues, 2004(4), 122-155.

Kurylowicz, J. (1964). The inflectional categories of Indo-European. Heidelberg: Carl Winters.

Latipov, R. A. (1992). German Studies: Subclasses of verbs of volition in Modern English. Saint Peterborough: Education.

Layons, D. (1978). Введение в теоретическую лингвистику [In Theoretical Linguistics]. Moscow: Progress

Novikova, O. N. (1989). Semantic-syntactical structure of the construction with verbs expressing volition in Modern English. Minsk: Minsk State University of Foreign Languages Press.

Palmer, F. R. (2001). Mood and Modality (2nd ed.). New York: Cambridge University Press.

Perkins, M. R. (1983). Modal Expressions in English. London: Pinter.

Rescher, N. (1968). Topics in Philosophical Logic. Dortrecht: Reidel.

Shestakova, O. B. (1995). Subjective modal meaning of "wish" and its actuality in discourse. Saint Peterborough: Nauk.

Simpson, P. (1993). Language, Ideology and Point of View. London: Routledge.

Swan, M., \& Walter, C. (2001). The Good Grammar Book. USA: Oxford University Press.

Tsangalides, A., \& Facchinetti, R. (2009). Studies on English Modality. Bern: Peter Lang.

Vasilyeva, E. P. (1999). Language and Culture: (Research on the Germanic language): Concept of non-addressed desire and the ways of expression in English. Samara: Samara University Press.

Alisova, T. E. (1971). Linguistics: Complementary relation of modus and dictum. Moscow: Nauka. 